\title{
Using the Miracle Question in Community Engagement and Planning
}

\author{
Leslie D. Hollingsworth, Paula Allen-Meares, Trina R. Shanks, \& Larry M. Gant
}

\begin{abstract}
Actively engaging community members in the revitalization of their neighborhoods is a goal of numerous planning initiatives. In this article, we provide a case example of how the solution-focused brief therapy's "miracle question" was used to engage members of a major metropolitan community in visualizing their dreams and planning strategies for change. Similar to outcomes with therapy clients, community members participated actively and were enthusiastic in communicating their outcomes. Dreams were realistic and important to participants, and suggested strategies were oriented toward first steps and recognized as involving effort by the community. Engagement and retention were sufficient to move forward with immediate actions and longer-term preparation. Benefits and suggested modifications are offered for community practitioners and researchers employing this method.
\end{abstract}

A ctively engaging community members in the revitalization of their neighborhoods is a goal of numerous planning initiatives. Although the solution-focused brief therapy's "miracle question" has been used in helping individuals and families plan their goals, there is no evidence of its application in community engagement and planning. In this article, we present a case example describing how the miracle question was used to engage families of a major metropolitan community in identifying their dreams and planning strategies for change in their neighborhoods.

\section{Background}

Solution-focused brief therapy is based in empowerment theory and directed toward building self-efficacy, learned resourcefulness, and internal locus of control (Greene, Lee, Mentzer, Pinnell, \& Niles, 1998). It focuses on what clients want to achieve rather than on the problem. Clients are asked to visualize what life would be like if the desired goal were realized:

\section{Suppose, after we finish here, you go home tonight, watch TV, do your usual chores, etc., and then go to bed and to sleep. And while you are sleeping, a miracle happens and the problems that brought you here are solved-just like that! But because this happens while you are sleeping, you cannot know that it has happened. Once you wake up in the morning, how will you [know] that this miracle has happened? (deShazer, n.d.)}

Other elements of solution-focused therapy are exception questions that examine (a) times when the problem did not exist; (b) scaling questions that measure where, on a scale of 1 to 10 and in relation to the miracle picture, clients rate their lives currently in order to plan next steps, measure progress, and evaluate goal attainment; and (c) end-of-session tasks, negotiated to assist with taking action (De Jong \& Miller, 1995). Greene and colleagues (1998) proposed a more empowering dream question in which clients had the resources needed to solve their problems.

In a comparison with two other therapeutic questioning stylesSocratic disputation (used in rational emotive therapy) and diagnostic interviewing of the type called for in the Diagnostic and Statistical Manual of Mental Disorders (DSM-IV-TR; American Psychiatric Association, 2000) - the miracle question was rated more highly by users as more participatory and supportive of autonomy (Bishop \& Fish, 1999). It is believed to involve a shift from unhelpful preoccupation with the problem to having an expectation of change and hope that one's life can be different (De Jong \& Miller, 1995; Greene et al., 1998; Klar \& Berg, 1999). In fact, Dine (1995) found that clients who used the miracle question reported changes in hope, mood, agency, and their perspective on the problem. Well-formed goals are key (De Jong \& Miller), characterized by being important to the client; small and manageable; concrete, specific, and behavioral; focused on presence versus absence; oriented toward beginnings or first steps; realistic; and recognized by the client as involving effort by them (Saleebey, 1992).

\section{Overview of the Community Planning Initiative}

The initiative in which the miracle question was used is a 10 -year urban planning initiative spearheaded and funded by a large philanthropic organization. It is being carried out in six neighborhoods in which about one third of the population is under 18 years of age. The city is unique among U.S. metropolitan communities in its early history of a large ethnic minority population, high resident achievement, active community participation, strong political involvement, and immense civic pride. Yet it is currently beset by social problems, including 
high unemployment, low high school graduation rates, low household incomes, high poverty rates, and high rates of mortgage foreclosures. Although serious crime has decreased, the city is still perceived as a dangerous place.

In this context, the outcome sought by the foundation was "to ensure that all children living in the six targeted neighborhoods are safe, healthy, well-educated, and prepared for adulthood." The foundation committed investment of its grant-making and change-making strategies. The authors are members of a university-based technical assistance team and collaborate with a major national community development organization and local partners. Families were recruited through the active efforts of community liaisons - residents of the targeted neighborhoods or the city itself-and were representative of the ethnic makeup of the largest populations of residents in each neighborhood. Word of mouth and snowball recruitment techniques were used, such as language- and group-specific outreach mailings and flyers; transportation, meals, and child care were provided at each community meeting.

Informal observation indicated that community members participating in the planning process were primarily African American middleto older-aged adults, with an equal number of men and women. Since the initiative was structured to include service providers affiliated with targeted neighborhoods, about one third of participants were provider representatives, although some of these were also residents.

The initiative consisted of three phases: planning, readiness, and transformation. Application of the miracle question occurred during the planning phase. In earlier meetings with small interest groups, stakeholder meetings, and larger community meetings, we had provided information about the initiative, solicited participant feedback on observations of the neighborhoods, and provided neighborhood demographic data for use in their subsequent planning. Based on their observations and the data provided, and having accepted the initiative's core goals and desired outcomes, participants decided on the overall goal that would frame their efforts. Participants took part in a group ceremony to acknowledge their commitment to the initiative. However, no individual commitment was requested or made. Although we did not systematically measure retention, $92.5 \%$ of the 80 participants completing a survey at a large community meeting (approximately 350 in the neighborhood from which the case was derived) said they had attended a previous meeting, and $93.8 \%$ said they intended to stay involved. Straw polls taken at each subsequent large meeting indicate that the vast majority of those present were not first-time attendees, suggesting retention.

\section{Use of the Miracle Question: The Case}

In engagement meetings with residents and other stakeholders of the first two neighborhoods, participants often became preoccupied with how bad things were, making it difficult to develop clear and realistic visions and strategies for change. In engagement meetings in the third and fourth neighborhoods, participants' dreams and suggested strategies overlapped, making coding difficult. Noting a similarity in obstacles to goal formation encountered in solution-focused therapy, we anticipated that the miracle question would be useful in our planning efforts and brought it into our work in the remaining two neighborhoods (Cohort II).

Application of the miracle question took place in special-interest resident focus groups and in the fourth large community meeting. The case presented here is that of Breakout Group 2, one of about 20 such groups meeting as part of the fourth large community meeting in Westlane (pseudonym for the actual neighborhood), a geographically recognized neighborhood of 17,563 residents within the larger metropolitan community. Twenty-six percent of Westlane residents are under 18 years old, and 94\% are African American. Approximately 17\% of households are headed by a single parent, the poverty rate is $31.2 \%$, and unemployment is $18 \%$. Thirty-three percent of residents are without a high school diploma, and overall home ownership is at $36 \%$ with a vacancy rate of $18 \%$.

The experienced facilitator (a White female) and recorder (an African American female) were similar ethnically to residents of the neighborhood in which the miracle question was presented and had been trained by the first author. Training included the history, purpose, and theoretical basis of the miracle question; recruiting and defining roles for group volunteers; and using probes or "satellite questions" (De Jong \& Miller, 1995). Participants had been assigned, upon their arrival, to a breakout group. Youth were randomly assigned from a separate pool to ensure approximately equal numbers of youth in each group. Since we were

TABLE 1. Dreams of Residents and Stakeholders by Theme (Group 2 Breakout)

\begin{tabular}{|c|c|}
\hline THEME & DREAM \\
\hline $\begin{array}{l}\text { Well-kept, attractive } \\
\text { neighborhoods }\end{array}$ & $\begin{array}{l}\text { Beautiful homes; vacant houses turned into redone, solar-paneled homes for the homeless; no liquor stores; no blight; } \\
\text { abandoned houses and buildings are torn down; modern neighborhood; no vacant lots; well-maintained homes; trees. }\end{array}$ \\
\hline $\begin{array}{l}\text { Community recreation } \\
\& \text { resource center }\end{array}$ & $\begin{array}{l}\text { Community centers with pools; personally-owned, abandoned building turned into a community center; real } \\
\text { playgrounds; resource centers; community centers that offer computer training; new, cleaned-up parks. }\end{array}$ \\
\hline Quality businesses & High-quality grocery stores; sit-down restaurants; black soul food restaurant; coffee shops; movie theaters. \\
\hline $\begin{array}{l}\text { Quality schools \& } \\
\text { educational services }\end{array}$ & $\begin{array}{l}\text { World-class high school and middle school equipped with everything; quality local schools; schools are well-funded; } \\
\text { kids who need special education are getting it; students are receiving financial education; state-of-the-art schools with } \\
\text { programs like robotics. }\end{array}$ \\
\hline Safe neighborhoods & $\begin{array}{l}\text { Safe playgrounds; no violence; no fear; a vibrant community that is safe; police walking the beat; neighborhoods are } \\
\text { safe with no abandoned buildings. }\end{array}$ \\
\hline Healthy families & Parents are parenting; no abused children; disciplined children who help other residents build up the community. \\
\hline Engaged, nurturing community & $\begin{array}{l}\text { Churches are involved in the community; churches are deeply invested in the community; people think about others; } \\
\text { putting love into action; residents involved in local churches; people respect each other; happy neighbors. }\end{array}$ \\
\hline
\end{tabular}

Effective, accessible public services

A two-truck fire house; streetlights working 
experimenting with using the miracle question, we chose to deviate from the original wording only in substituting dreams for miracles, in keeping with the proposal by Greene and colleagues (1998):

Imagine you've gone to sleep and while you're sleeping, you have a dream. And in your dream, Westlane becomes exactly the way you'd like to see it. In your dream, Westlane is a proactive community organized to provide high-quality education and resources to meet the needs of its children and families. [Note: This is the overall goal adopted by Westlane families and other stakeholders.] Keeping your eyes closed: What do you see that lets you know the goal has been accomplished, that your dream has become a reality?

Individual dreams were recorded and guided a subsequent full-group conversation about potential strategies needed for dreams to become a reality. After the 50-minute breakout session, two persons, selected by the group, reported to the reconvened larger group.

A content analysis was conducted of data representing participants' dreams and strategies. The first and fourth authors independently coded Westlane Group 2 data. From an exhaustive initial list of emerging themes, we eliminated duplications and agreed on themes to be used for the next round of coding. Percentage agreement between coders was subsequently calculated by the first author.

\section{Results}

Table 1 contains the dreams of Westlane neighborhood Group 2 participants coded under the same themes by both coders. Themes that emerged were of well-kept, attractive neighborhoods; community recreation and resource centers; quality businesses; quality schools and educational services; safe neighborhoods; healthy families; an engaged, nurturing community; and effective, accessible public services. Percentage agreement between coders for dreams coded in this one group was 78.5 , with agreement in 51 cases, disagreement in 14 , and one not coded by the second coder. This is slightly below the 0.80 recommended by Hartmann (1977) and Krippendorff (1980) as a minimum standard for reliability. Disagreements reflected differences in interpretation of the meaning of themes and demonstrated the necessity for clarity in theme definitions. The largest number of agreements was for dreams coded under the theme of well-kept, attractive neighborhoods, and most others were distributed equally among the remaining themes.
Table 2 consists of coded strategies suggested by members of Group 2. The largest number was coded under the theme of community building and organizing. Others were distributed among themes related to job finding, preparation, and training; securing funding; strategic planning; publicity, marketing, and public relations; and establishing partnerships. Percentage agreement in items coded was 96.3, with agreement in 27 of 28 items coded and one item not coded by one coder. Themes were consistent with those that emerged from coding of all other Cohort II breakout group data.

\section{Next Steps}

Strategy themes directed the establishment of action-planning teams that implemented short-term plans and planned longer-term interventions, particularly in preparation for the readiness phase of the initiative. Examples of short-term activities were block clubs; youth summits; community resource fairs; neighborhood newsletters; neighborhood cleanup campaigns; partnerships with public safety, education, local businesses, and human service providers; and public and private linkages in job finding, preparation, and training. A structure for community governance of the initiative is being established, leadership development training has begun, and skills workshops are being offered in such areas as strategic planning, grassroots fundraising, and formal grantwriting. The transformation phase will involve implementation of long-range community plans within the established governance structure.

\section{Discussion}

Interestingly, dreams described in the case presented reflect values that characterized city residents historically-high achievement orientation, active involvement, community connectedness, and community pride. Strategies were consistent with the overall goal adopted earlier by the Westlane community that included such language as "a proactive community," "organized," "high-quality education," "resources," and "needs of children and families."

Dreams and strategies that emerged from Westlane's Group 2 also demonstrated several characteristics of well-formed goals, as described by Saleebey (1992), and reflected the empowering nature of this approach, discussed by Greene and colleagues (1998). For example, dreams were clearly about community changes that were realistic and important to participants. Strategies emphasized the necessity of change in community values as a first step and of effort by the community in making their dreams a reality. Both dreams and strategies reflected the

TABLE 2. Strategies Suggested by Families and Stakeholders by Theme (Group 2 Breakout)

\begin{tabular}{|c|c|}
\hline THEME & StRategies \\
\hline $\begin{array}{l}\text { Community building and organizing } \\
\text { (youth and adults) }\end{array}$ & $\begin{array}{l}\text { Community participation; education; volunteers; faith; work, more sacrifice; persistence; teamwork; leadership; } \\
\text { changing community mind-set; motivators; youth involved; restore the pride; respect self and others; love yourself. }\end{array}$ \\
\hline Strategic planning & Blueprints. \\
\hline Securing funding & Grants; funding; local investors; donations. \\
\hline Publicity/ marketing/ public relations & Publicity; get the word out about these meetings, inside and outside of the community. \\
\hline Establishing partnerships & Partner with police, neighborhood liaisons; citizens' band (CB) radio patrols; community partnerships: local, state, federal. \\
\hline Job finding/ preparation/ training & $\begin{array}{l}\text { Creating jobs for youth; jobs for all; trade schools and local colleges; youth center w/ volunteers who will style } \\
\text { youngsters' hair and provide clothing for job interviews-both of which are provided to youth at low or no cost. }\end{array}$ \\
\hline
\end{tabular}


hope, mood, agency, and perspective on the community's problems, described by Dine (1995), and compared positively to the focus by many in earlier meetings on how bad things were in the neighborhoods.

\section{Benefits}

Applying the miracle question to engaging communities yielded benefits and challenges. Facilitators were easily trained within a short time period and were excited about the method. Those following the training script showed more uniformity in process and outcomes. Training also allowed feasibility testing. For example, our decision to move to strategizing as a full group resulted from lessons learned during facilitator training about the time constraints facilitators would face.

Participants seemed "to get" the intent of the miracle question. This was particularly apparent in the large group report-out session, where vivid dreams were identified and sound strategies put forth, all in an atmosphere of excitement, support, and inspiration, leading one observer to comment on how similar the dreams and strategies were across the many groups.

\section{Challenges}

Multiple challenges were also present and led us to recommend modifications, specifically: (a) sufficient time for the miracle question, including time for probes and satellite questions; (b) manuals to increase uniformity; (c) facilitators and recorders who represent identity groups of interest, in addition to language- and group-specific outreach and interpreters; (d) definitions of key terms; (e) multiple coders to increase reliability of themes identified (except in the case discussed here, single coders were used); (f) a system acceptable to the community for collecting demographics and measuring retention and commitment; $(\mathrm{g})$ stratifying small group assignments to ensure diversity; (h) comparison of the miracle question with another method and the "miracle" with "dreams and strategies" language; and (i) examining the role of the miracle question in the systematic evaluation of the larger planning initiative.

\section{Conclusions and Implications}

The case presented here represents an exploratory application of the miracle question in engaging members of a major metropolitan community in a neighborhood revitalization planning process. The approach was successful in engaging participants and eliciting positive and realistic pictures of desired changes. Strategies elicited provided direction for first steps in community responsibility and partnering with other entities. We believe the benefits noted are sufficient to encourage practitioners' use of the miracle question in their similar community engagement and planning efforts, with consideration given to the limitations noted and modifications recommended.

\section{References}

American Psychiatric Association. (2000). Diagnostic and Statistical Manual of Mental Disorders (4th ed., text revision). Washington, DC: Author.

Bishop, W., \& Fish, J. M. (1999). Questions as interventions: Perceptions of Socratic, solution focused, and diagnostic questioning styles. Journal of RationalEmotive and Cognitive-Behavior Therapy, 17, 115-140.

De Jong, P., \& Miller, S. D. (1995). How to interview for client strengths. Social Work, 40, 729-736.

deShazer, S. (n.d.). The miracle question. Retrieved November 28, 2007, from http:// www.brief-therapy.org/steve_miracle.htm

Dine, K. R. (1995). The miracle question and the possibility of change. Dissertation Abstracts International, 56, 6B. (UMI No. AAM9536336)

Greene, G. J., Lee, M., Mentzer, R. A., Pinnell, S. R., \& Niles, D. (1998). Miracles, dreams, and empowerment: A brief therapy practice note. Families in Society: The Journal of Contemporary Human Services, 79, 395-399.

Hartmann, D. P. (1977). Considerations in the choice of interobserver reliability estimates. Journal of Applied Behavior Analysis, 10, 103-116.

Klar, H., \& Berg, I. K. (1999). Solution-focused brief therapy. In D. M. Lawson \& F. F. Prevatt (Eds.), Casebook in family therapy (pp. 232-258). Belmont, CA: Wadsworth.

Krippendorff, K. (1980). Content analysis: An introduction to its methodology. Beverly Hills, CA: Sage.

Saleebey, D. (Ed.). (1992). The strengths perspective in social work practice. New York: Longman.

Leslie D. Hollingsworth, $\mathrm{PhD}$, ACSW, LMSW, is associate professor, University of Michigan School of Social Work. Paula Allen-Meares, PhD, is chancellor, University of Illinois at Chicago and John Corbally Presidential Professor.

Trina R. Shanks, PhD, LMSW, is assistant professor, and Larry M. Gant, PhD, LMSW, is professor, University of Michigan School of Social Work. Correspondence regarding this article can be sent to the first author at lholling@umich.edu or School of Social Work, 1080 South University, Ann Arbor, MI 48109-1106.

Authors' note. Our appreciation is expressed for the assistance of our project manager Patricia Miller, project coordinator Kristin McGee, assistant Tammy Miller, and editor Tanya Emley.

Manuscript received: March 17, 2008

Revised: September 30, 2008

Accepted: October 14, 2008 